\title{
Obesity among women of reproductive age using contraceptive methods in Port Harcourt, Nigeria
}

\author{
Njoku Patrick U ${ }^{1}$, Dienye Paul 0 2, ${ }^{*}$, Olaniyan Fatai A ${ }^{3}$, Iloh Gabriel UP ${ }^{1}$ and Njoku Roseline AN ${ }^{4}$ \\ 1 Department of Family Medicine, Federal Medical Centre Umuahia, Abia State, Nigeria. \\ 2 Department of Family Medicine, University of Port Harcourt Teaching Hospital, Port Harcourt, Nigeria.. \\ ${ }^{3}$ Department of Staff Medical Services, University College Hospital, Ibadan, Nigeria. \\ ${ }^{4}$ Pharmacy Department, Federal Medical Center, Umuahia, Nigeria.
}

Publication history: Received on 10 April 2020; revised on 20 April 2020; accepted on 22 April 2020

Article DOI: https://doi.org/10.30574/wjarr.2020.6.1.0096

\begin{abstract}
Obesity predisposes pregnant women to increased risk of pregnancy complications for mother and fetus. Avoiding unintended pregnancy among obese women is therefore of major importance, given the increased risks associated with pregnancy. This study determined the prevalence of obesity among female contraceptive users in the University of Port Harcourt Teaching Hospital. This was a cross-sectional study among randomly selected married non-pregnant women of reproductive age attending the Family Medicine clinic. Data was collected using a specially designed structured questionnaire and analysed using SPSS version 20. The p-value of less than 0.05 was used as the criterion for significance. A total of 422 randomly selected participants who satisfied the inclusion and exclusion criteria were studied. Their age range was $15-49$ years with a mean of $32.86 \pm 6.85$ years. Majority of the respondents (60.7\%) had 13-18 years of formal education. The contraception prevalence among obese participants was $37.2 \%$. The barrier method was the most commonly used (32.6\%). There was no association between contraceptive use and the participants' Body Mass Index ( $\mathrm{p}=0.730)$. The prevalence of obesity among contraceptive users was $37.2 \%$. The barrier method was the most commonly used method. Although there was no association between contraceptive use and obesity, primary care providers including family physicians should educate women on the adverse effect of obesity on the general health of women.
\end{abstract}

Keywords: Contraceptive use; obesity; Nigeria

\section{Introduction}

The global rate of obesity is very high with one billion and 300 million adults meeting the criteria for overweight and obesity respectively [1]. There are many ways to quantify obesity, the most common being the BMI (BMI = weight in kilograms divided by the square of height in meters $\left(\mathrm{kg} / \mathrm{m}^{2}\right)$. BMI provides a continuous measurement of weight-forheight, with cutoffs for overweight and different classes of obesity. The accepted classification of body mass index published by both the WHO [2] and the National Institute for Health and Clinical Excellence (NICE) [3] is as follows:

- Underweight $<18.5 \mathrm{~kg} / \mathrm{m} 2$

- Normal $18.5-24.9 \mathrm{~kg} / \mathrm{m}^{2}$

- Overweight $25-29.9 \mathrm{~kg} / \mathrm{m}^{2}$

- Obese $\geq 30 \mathrm{~kg} / \mathrm{m}^{2}$

Obesity among pregnant women predisposes them to pregnancy complications for mother and fetus [4, 5]. It also makes procedure-dependent contraceptive methods such as sterilization and insertion of intrauterine devices, technically challenging for the provider to perform [6]. Even with these problems associated with obesity, there is the social desire

\footnotetext{
${ }^{*}$ Corresponding author: Dienye Paul 0
} 
for fat women in some cultures. An example is the premarital "fattening rooms" among the Annang people in the SouthSouth geopolitical zone of Nigeria [7]. This practice predisposes them to the complications of obesity during pregnancy.

Contraceptive use has increased substantially over the past decades worldwide due to the improvement on existing contraceptive methods and the development of several new more effective and acceptable methods, with fewer sideeffects [8]. In addition, some contraceptive methods have been reported to offer important non-contraceptive benefits for women $[9,10]$.

Considering the pregnancy complications associated with obesity, preventing unintended pregnancy by the use of contraceptives is as important for obese women, as for women contending with any chronic health condition. Unfortunately, there exist obstacles to contraceptive use in developing countries. These include the negative influence of husbands who may feel that it is an encouragement of wives to be unfaithful, the fear of loss of authority as head of the family, and their desire for large number of children [11,12]. Among the women, some are uninformed about the benefits of contraceptive use [13].

Little is known about the BMI of contraceptive-seeking women in the University of Port Harcourt Teaching Hospital, yet it is important that providers deliver contraceptive counseling that incorporates the best available evidence. This study was therefore designed to determine the prevalence of obesity among female contraceptive users in the University of Port Harcourt Teaching Hospital.

\section{Material and methods}

\subsection{Study site}

This study was carried out in the Family Medicine Clinic, University of Port-Harcourt Teaching Hospital, Nigeria. Its catchment areas include neigbouring Imo, Akwa Ibom, Bayelsa and Abia States.

\subsection{Study design}

This was a cross-sectional hospital based study which was conducted in four weeks.

\subsection{Study population}

The subjects consisted of only married non-pregnant women of reproductive age (15- 49 years of age) in nuclear families attending the family medicine clinic. All the women outside the reproductive age (15-49 years of age), pregnant women, married women not of nuclear families, single women of reproductive age, women with prior hysterectomy, those who declined consent, divorced and widowed women were excluded from the study.

\subsection{Sample size}

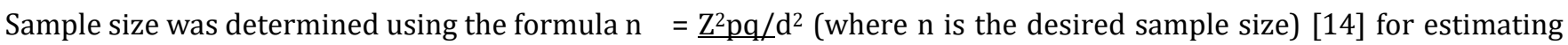
minimum sample size for descriptive studies when studying proportions with entire population size $>10,000$. There was no known reasonable estimate of the prevalence of obesity among contraceptive users in the environment of the study hence $50 \%$ was used to derive the minimum sample size [15]. The derived figure was 384 but was increased by $10 \%$ to make room for attrition. Thus the desired sample size was 422 .

\subsection{Sampling method}

A systematic sampling method was used to select the participants.

\subsection{Study instrument}

This included a specially designed, structured and pretested questionnaire developed by the researcher and a stadiometer (Seca Corporation, Maryland, United State of America) used for measuring the subjects heights (meters) and body weights (kilogram).

\subsection{Data collection}

The data collection was through the questionnaire by the researcher. The questionnaire administration was done after careful explanation of the study to ensure confidentiality and consent extraction. Data on the socio-demographic characteristics and current contraceptive method were collected. The stadiometer was used to measure height and 
weight. To measure the height, the participants' were asked to take off her shoes, hats or head ties; stand with back to the rigid meter rule on the stadiometer; and hold their head in a position where she can look straight at a spot, head high, on the opposite wall. A flat rule was placed on the participant's head, so that the hair (if present) was pressed flat. Height was measured to the nearest meter, at the level where the flat rule touched the rigid meter rule. To measure weight, participants were asked to remove heavy outer garments, empty their pockets and step on the stadiometer, which was placed on a hard, even surface. Weight was measured to the nearest kilogram.

\subsection{Data analysis}

The data collected was fed into SPSS version 14. Tables and Charts were constructed for presentation of the results. Statistical analysis employed included percentages, frequencies and mean. The chi-square test was used in assessing the significant associations between categorical groups. A P-value of $<0.05$ was considered statistically significant.

\subsection{Ethical consideration}

The approval of the hospital ethical committee was obtained. Also consents of all the subjects were obtained before inclusion in the study. Consent was also obtained from spouses of participants less than 18 years of age. The ethical principles for the guidance of physicians in medical research were observed $[16,17]$.

\section{Results}

Four hundred and twenty two randomly selected non-pregnant women of reproductive age who satisfied the inclusion and exclusion criteria were enrolled. The ages of the respondents ranged from 15-49 years with mean age of $32.86 \pm$ 6.85 years.

Table 1 Distribution of the socio-demographic characteristics of the respondents

\begin{tabular}{|c|c|c|}
\hline Characteristics & Frequency (n) & Percentage of total \\
\hline \multicolumn{3}{|l|}{ Age distribution } \\
\hline $15-29$ & 2 & 0.5 \\
\hline $20-24$ & 36 & 8.5 \\
\hline $25-29$ & 118 & 28.0 \\
\hline $30-34$ & 111 & 26.3 \\
\hline $35-39$ & 72 & 17.1 \\
\hline $40-44$ & 48 & 11.4 \\
\hline $45-49$ & 35 & 8.3 \\
\hline \multicolumn{3}{|l|}{ Educational duration } \\
\hline $1-6$ & 37 & 8.8 \\
\hline $7-12$ & 117 & 27.7 \\
\hline $13-18$ & 256 & 60.7 \\
\hline $19-24$ & 12 & 2.8 \\
\hline \multicolumn{3}{|l|}{ Religion } \\
\hline Christianity & 406 & 96.2 \\
\hline Islam & 5 & 1.2 \\
\hline Traditional & 3 & 0.7 \\
\hline Others & 8 & 1.9 \\
\hline \multicolumn{3}{|l|}{ Occupation } \\
\hline Artisan & 23 & 5.4 \\
\hline Civil Servant & 46 & 10.9 \\
\hline Corper (NYSC* members) & 3 & 0.7 \\
\hline Farmer & 11 & 2.6 \\
\hline High level profession & 51 & 12.1 \\
\hline Housewife & 64 & 15.2 \\
\hline Pastor(clergy women) & 3 & 0.7 \\
\hline Student & 71 & 16.8 \\
\hline Teacher & 53 & 12.6 \\
\hline Trader & 97 & 23.0 \\
\hline
\end{tabular}


A significant proportion of the respondents (28.0\%) were aged between 25 and 29 years while those aged $15-19$ years formed the least (0.5\%). Majority of the respondents (60.7\%) had 13-18years of formal education while only $2.8 \%$ of the respondents had 19-24 years of education. Almost all the respondents (96.2\%) belonged to the Christian religion. The largest proportion of the respondents (16.8\%) was students. Pastors (Clergy women) and National Youth Service Corp members constituted $0.7 \%$ each (Table 1 ).

The barrier method (condom) was the most commonly used contraceptive method (32.6\%) followed by the billing method $(23.3 \%)$ while the withdrawal method $(2.3 \%)$ was the least contraceptive method being used by contraceptive users (Table 2).

Table 2 Types of contraceptive method currently being used by the respondents

\begin{tabular}{|c|c|c|}
\hline Contraceptive method currently used & Frequency $(n=215)$ & Percentage \\
\hline Barrier method (Condom) & 70 & 32.6 \\
\hline Billing/Rhythm & 50 & 23.3 \\
\hline Implants & 15 & 7.0 \\
\hline Injectibles & 26 & 12.1 \\
\hline Intrauterine contraceptive device & 19 & 8.8 \\
\hline Oral contraception pill & 24 & 11.1 \\
\hline Voluntary surgical contraception & 6 & 2.8 \\
\hline Others (withdrawal) & 5 & 2.3 \\
\hline
\end{tabular}

Considering the relationship between type of contraceptive utilization and respondent's body mass index, out of the 215 respondents using contraceptive methods, the proportion with normal body mass index was $25.1 \%$, obesity (37.2\%), overweight $(37.2 \%)$ and underweight $(0.5 \%)$. The barrier method (condom) was the most commonly used contraceptive method in all the BMI categories though it was most commonly used by those with obesity and overweight. However, there was no association between type of contraceptive utilization and respondents' body mass index $(\mathrm{p}=0.730)$ (Table 3).

Table 3 Relationship between Respondents' contraceptive utilization and BMI categories

\begin{tabular}{|c|c|c|c|c|c|c|c|}
\hline \multirow[t]{2}{*}{ Types of contraceptive used } & \multicolumn{4}{|c|}{ Body mass Index(BMI) } & \multirow{2}{*}{$\begin{array}{l}\text { Total } \\
\mathrm{N}=215\end{array}$} & \multirow[t]{2}{*}{$\chi 2$} & \multirow{2}{*}{$\begin{array}{l}\text { P- } \\
\text { value }\end{array}$} \\
\hline & $\begin{array}{l}\text { Normal } \\
n=54(\%)\end{array}$ & $\begin{array}{l}\text { Obesity } \\
n=80(\%)\end{array}$ & $\begin{array}{l}\text { Over } \\
\text { weight } \\
n=80(\%)\end{array}$ & $\begin{array}{l}\text { Under- } \\
\text { weight } \\
n=1(\%)\end{array}$ & & & \\
\hline Barrier method (Condom) & $19(35.2)$ & $23(28.8)$ & $28(35.0)$ & $0(0.0)$ & $70(32.6)$ & \multirow{8}{*}{16.68} & \multirow{8}{*}{0.7302} \\
\hline Billing/Rhythm & $11(20.4)$ & $20(25.0)$ & $19(23.8)$ & $0(0.0)$ & $50(23.3)$ & & \\
\hline Implants & $3(5.6)$ & $5(6.3)$ & $7(8.8)$ & $0(0.0)$ & $15(7.0)$ & & \\
\hline Injectibles & $10(18.5)$ & $7(8.8)$ & $8(10.0)$ & $1(100.0)$ & $26(12.1)$ & & \\
\hline IUCD & $3(5.6)$ & $9(11.3)$ & $7(8.8)$ & $0(0.0)$ & $19(8.8)$ & & \\
\hline Oral contraceptives & $5(9.3)$ & $11(13.8)$ & $8(10.0)$ & $0(0.0)$ & $24(11.2)$ & & \\
\hline $\begin{array}{l}\text { Voluntary } \\
\text { contraceptive }\end{array}$ & $1(1.9)$ & $4(5.0)$ & $1(1.3)$ & $0(0.0)$ & $6(2.8)$ & & \\
\hline Others (withdrawal) & $2(3.7)$ & $1(1.3)$ & $2(2.5)$ & $0(0.0)$ & $5(2.3)$ & & \\
\hline
\end{tabular}




\section{Discussion}

This study was aimed to determine the prevalence of obesity among contraceptive users in the Family Medicine Clinic in University of Port Harcourt Teaching Hospital; Nigeria found a prevalence of 37.2\%. This is higher than the prevalence of $25.1 \%$ among participants with normal BMI. The comparatively high contraceptive use by the obese participants is commendable considering its adverse effect on pregnancy especially if unintended. Pregnancy in an obese woman predisposes her to complications such as pre-eclampsia, wound infections, anaesthetic complications, miscarriages, cardiovascular problems and consequent maternal death. These obstetric complications are potentially higher in low resource settings where specialized care for obstetric and medical problems associated with obesity may be suboptimal [18]. It also adversely affects the health of future generations with increased rates of obesity and diabetes in the offspring [4]. Obesity may make procedure-dependent contraceptive methods such as sterilization and insertion of IUD more challenging for the provider to perform predisposing to increased rate of complications among them [19]. Intramuscular injections may also require longer needles to achieve appropriate medication delivery [20]. Unintended pregnancy and childbirth carries a lot risks for the mother and child. The woman has to either carry the pregnancy to term or have an induced abortion [21] which is illegal in Nigeria. Births that are unintended by the mother places her at elevated risks of adverse social, economic, and health outcomes for her and the child [22]. Unintended pregnancy in an obese woman is a condition that should be avoided hence frontline practitioners such as family physicians and nurses should utilize all contacts with obese women as avenue for health education on the importance of contraceptive use.

The $37.2 \%$ prevalence in this study is substantial yet considerably lower than the $42 \%$ reported by Akarolo-Anthony et al for the general reproductive-aged adult female population in Abuja, an urban city in Nigeria [23]. This comparatively lower prevalence than in the general population is not expected because of certain characteristics in the participants of this study predisposing them to obesity but may not be present in the Abuja study participants that consisted of married and unmarried civil servants. These characteristics include the fact that all of the participants in our study consisted of married women who would have been exposed to the weight gain during and after pregnancy [24], and some of them are exposed to the "fattening room" practice which is rife among the women in the area [7]. Also sedentary lifestyle is common in Port Harcourt sequel to the high crime rates such as kidnapping at night and high traffic. These may discourage jogging and other forms of exercises outside their homes thus promoting obesity [25].

The barrier method was the most widely used contraceptive method in this study. Similar finding had been reported by other researchers [26,27]. This observation could be a reflection of the high level of education among the respondents and little or no side effects associated with condom use. Education is known to improve correct use of contraceptive methods and interpersonal communication. Also the cheapness and wide availability of condoms, and the present HIV/AIDS scourge may have contributed to this finding too since the condom is known to prevent its infection.

Strengths of our study include the prospective design and objective assessment of weight and BMI. There is dearth of literature on the body mass index of women of reproductive age using contraceptive methods in Port Harcourt and this study begins to fill that knowledge gap.

Our study is not without limitations. As an observational study, the demographic characteristics of our participants may differ from other populations, in turn limiting the generalizability of our findings.

\section{Conclusion}

The prevalence of obesity among contraceptive users was 37.2\%. The barrier method was the most commonly used method. Although there was no association between contraceptive use and obesity, primary care providers including family physicians should educate women on the adverse effect of obesity on pregnancy hence embrace contraceptive use.

\section{Compliance with ethical standards}

\section{Acknowledgments}

We would like to thank the University of Port Harcourt Teaching Hospital for providing an ethical clearance for this research. We also thank the Head of Department of Family Medicine and the patients who were very cooperative during data collection. 


\section{Disclosure of conflict of interest}

Authors have declared no conflict of interests.

\section{References}

[1] World Health Report. (2002). Overweight, obesity, and high body mass, 60.

[2] World Health Organization. (2000). Obesity: Preventing and managing the global epidemic. Geneva: World Health Organization.

[3] National Institute for Health and Clinical Excellence. (2006).Obesity. Guidance on the Prevention, Identification, Assessment and Management of Overweight and Obesity in Adults and Children. London: National Institute for Health and Clinical Excellence (NICE).

[4] Catalano PM and Ehrenberg HM. (2006). The short- and long-term implications of maternal obesity on the mother and her offspring. BJOG, 113, 1126-33.

[5] American College of Obstetricians and Gynecologists. (2009). ACOG Practice Bulletin No. 105: bariatric surgery and pregnancy. Obstet Gynecol, 113, 1405-1413.

[6] Hammond KL. (2013). Practical issues in the surgical care of the obese patient. Ochsner J, 13(2), 224-7.

[7] Brink PJ. (1989). The fattening room among the Annang of Nigeria. Med Anthropol, 12, 131-43.

[8] Abasiattai AM. (2006). Current Concepts in Contraception. Nig. J Med, 15(4), 364-72.

[9] Guleria K, Agarwal N, Mishra K, Gulati R and Mehendiratta A. (2004). Evaluation of endometrial steroid receptors and cell mitotic activity in women using copper intrauterine device: $\mathrm{Can} \mathrm{Cu}-\mathrm{T}$ prevent endometrial cancer? J Obstet Gynaecol Res, 30, 181-7.

[10] Varma R, Sinha D and Gupta JK. (2005). Non-contraceptive uses of levonorgestrel- releasing hormone system (LNG-IUS) - A systematic enquiry and overview. Eur J Obstet Gynecol Reprod Biol, 125, 9-28.

[11] Mistik S, Nascar M, Mazicioglu M and Cetinkaya F. (2003). Married men's opinions and involvement regarding family planning in rural areas, Contraception, 67(2), 133-7.

[12] Adogu OU and Obionu ON. (2007). Factors responsible for non-acceptance of modern family planning methods by married men in two rural local government areas of Nigeria. The Tropical J Health Sci., 14(1), 15-9.

[13] Michael R and Heffion WA. (2002). Preventive health care. In Rakel RE(ed). Textbook of Family Practice Sixth edition Saunders, New York, 183-209.

[14] Araoye MO. (2004). Research Methodology with Statistics for health and social sciences. 1st edition Ilorin, Nigeria. Nathadex, Ilorin Nigeria, 115-29.

[15] Pourhoseingholi MA, Vahedi M and Rahimzadeh M. (2013). Sample size calculation in medical studies. Gastroenterol Hepatol Bed Bench, 6(1), 14-7.

[16] Idanpaan - Heikkila JE. (2001). Ethical principles for the guidance of physicians in medical research - the Declaration Helsinki. Bulletin of WHO, 79(4), 279.

[17] World Medical Association Declaration of Helsinki. (2001).Ethical principles for medical research involving human subjects Bulletin of WHO, 79(4), 373-4.

[18] Kanguru L, McCaw-Binns A, Bell J, Yonger-Coleman N, Wilks R and Hussein J. (2017). The burden of obesity in women of reproductive age and in pregnancy in a middle-income setting: A population based study from Jamaica. PLoS One, 12(12), e0188677.

[19] Jamieson D, Hillis S, Duerr A, Marchbanks P, Costello C and Peterson H.(2000). Complications of interval laparoscopic tubal sterilization: findings from the United States Collaborative Review of Sterilization. Obstet Gynecol, 96, 997-1002.

[20] Nisbet A. (2006). Intramuscular gluteal injections in the increasingly obese population: retrospective study. BMJ, $332,637-8$.

[21] Moss DA, Snyder MJ and Lu L. (2015). Options for women with unintended pregnancy. Am Fam Physician, 91, 544-9. 
[22] David HP. (2006). Born unwanted, 35 years later: The Prague study. Reprod Health Matters, 14, 181-90.

[23] Akarolo-Anthony S N, Willett WC, Spiegelman D and Adebamowo CA. (2014). Obesity epidemic has emerged among Nigerians. BMC Public Health, 14, 455.

[24] Holdsworth M, Gartner A, Landais E, Maire B and Delpeuch F. (2004). Perceptions of healthy and desirable body size in urban Senegalese women. Int J Obes Relat Metab Disord, 28, 1561-1568.

[25] Oyeyemi AL, Adegoke BO, Oyeyemi AY, Deforche B, De Bourdeaudhuij I and Sallis JF. (2012). Environmental factors associated with overweight among adults in Nigeria. Int J Behav Nutr Phys Act, 9, 32.

[26] Omolase CO, Faturoti SO and Omolase BO. (2008). Pattern of family planning methods used by antenatal patients in Owo, Nigeria. Nig Hosp Pract, 2(2), 33-6.

[27] Kayembe PK, Fatuma AB, Mapatan MA and Mambu T. (2006). Prevalence and determinants of the use of modern contraceptive methods in Kinshasa, Democratic Republic of Congo. Contraception, 74(5), 400-6.

\section{How to cite this article}

Njoku PU, Dienye PO, Olaniyan FA, Iloh GUP and Njoku RAN. (2020). Obesity among women of reproductive age using contraceptive methods in Port Harcourt, Nigeria. World Journal of Advanced Research and Reviews, 6(1), 159-165. 